\title{
Knowledge Discovery in Learning Management System Using Piecewise Linear Regression
}

\author{
S. Mythili1', R. Pradeep Kumar¹, P. Nagabhushan ${ }^{2}$ \\ ${ }^{1}$ Department of Computer Science, United Institute of Technology, Anna University, Chennai, India \\ ${ }^{2}$ Department of Computer Science University of Mysore, Mysore, India \\ Email: mythili.uit@gmail.com
}

How to cite this paper: Mythili, S., Pradeep Kumar, R. and Nagabhushan, P. (2016) Knowledge Discovery in Learning Management System Using Piecewise Linear Regression. Circuits and Systems, 7, 3862-3873. http://dx.doi.org/10.4236/cs.2016.711322

Received: April 28, 2016

Accepted: May 25, 2016

Published: September 23, 2016

Copyright $\odot 2016$ by authors and Scientific Research Publishing Inc. This work is licensed under the Creative Commons Attribution International License (CC BY 4.0).

http://creativecommons.org/licenses/by/4.0/ (c) (i) Open Access

\begin{abstract}
Recent developments in database technology have seen a wide variety of data being stored in huge collections. The wide variety makes the analysis tasks of a generic database a strenuous task in knowledge discovery. One approach is to summarize large datasets in such a way that the resulting summary dataset is of manageable size. Histogram has received significant attention as summarization/representative object for large database. But, it suffers from computational and space complexity. In this paper, we propose an idea to transform the histogram object into a Piecewise Linear Regression (PLR) line object and suggest that PLR objects can be less computational and storage intensive while compared to those of histograms. On the other hand to carry out a cluster analysis, we propose a distance measure for computing the distance between the PLR lines. Case study is presented based on the real data of online education system LMS. This demonstrates that PLR is a powerful knowledge representative for very large database.
\end{abstract}

\section{Keywords}

Histogram, Piecewise Linear Regression, Knowledge Discovery, Big Data, Cluster Analysis

\section{Introduction}

Knowledge Discovery in Databases (KDD) is defined as the nontrivial process of identifying valid, novel, potentially useful, and ultimately understandable patterns in data [1]. It has become a very important process to all the businesses and organization since it provides useful information that is most important to the business and future business decisions. In order to discover the knowledge from large volumes of data, undoubtedly the term data mining pops up, since data mining is the field which can han- 
dle large volumes of data and can derive useful knowledge from it [2]-[4].

As we live in a digital world, there is a steady increase in accumulation of structured and unstructured data from various sources such as transactions, social media, sensors, digital images, videos, audios and click streams for domains including healthcare, retail, energy and utilities. For instance observation [5] reveals that 3 billion contents are being shared on Facebook every month; the photos viewed every 16 seconds in Picasa could cover a football field. Such a massive volume of data storage is generally termed as "Big Data". Turning big data into knowledge becomes a challenging task. However standard statistical methods cannot be made applicable directly to represent such huge data. Therefore the open challenge in big data is big data analysis which concerns in organizing and analyzing large sets of data to discover patterns and knowledge.

To incorporate new concepts in knowledge representation, Diday [6] has introduced a phrase called Symbolic Data Analysis (SDA). SDA refers to summarizing a large dataset in such a way that the resulting summary dataset is of a manageable size and yet retains as much of the knowledge in the original dataset as possible. These summarized data are termed as symbolic data [7] [8]. In general, it is contrasted with classical data in which each data point consists of a single (categorical or quantitative) value, where symbolic data can contain internal variation (list, ranges, etc.) and can be structured. In that very important sense, SDA can be considered a method for Big Data [9].

Our objectives in this paper are to propose a new idea of histogram based piecewise linear regression method, to summarize very large datasets, to produce smaller datasets in order to enhance the data mining technique to mine knowledge pattern in big data. Section 2 presents a brief literature review about symbolic data analysis and provides reasons for selection of PLR. Sections 3 describes histograms based piecewise linear regression lines. Also we propose the distance measure between two piecewise linear regression features. Section 4 furnishes the case studies on online education system to evaluate and discover the knowledge. Section 5 provides conclusion.

\section{Literature Review on Symbolic Data Analysis}

As in [11], interval data, multi-valued data and histogram data are described as major types of symbolic data. Histogram has been projected as a feature type, possessing the generality to characterize all other feature types like single valued, multi-valued, interval valued [10]. It has received significant attention as summarization/representative object. Moreover, interval data and multi-valued data [11] [12] are impossible to adapt all classical arithmetic formulations that apply to the single-valued data to interval-data without making the appropriate amendments. Hence we use histogram as the symbolic data to represent the concept descriptions. Subsequently, distance between the histograms has been proposed [13]-[15] in order to cluster a set of data described by distribution.

Also in the case of histogram there are some disadvantages. It is observed that algorithms for producing histograms are required to have the same number of bins and same bin width for all datasets for the effective characterization of data into histograms 
[16]. So storage of histograms requires memory for number of bins, bin width and memory for the details of each bin. Moreover by making a series of arithmetic operations on a number of histograms, the resulting histogram is expected to have a high number of intervals [17].

To overcome the disadvantages, an idea has been proposed [10] [16] [17] to model the histogram through a suitable basis function. Therefore parameters for histograms such as bin width, number of bins etc will not be of concern. Simona Signorillo [16] [18] approximated histogram using a B-spline. The challenge in that is to choose the number of optimal knots. The other basis function used is linear regression line to model the histogram. This model drastically reduces the computational complexity which holds more details about the data in a compressed form which requires only two parameters-slope and intercept. Also it reduces the memory requirement. It is further shown that regression line is a powerful knowledge representative [17] [19].

Analysis on regression model shows that, single linear regression line is not always "best fit" for the histogram model because it suffers from appropriateness by maximizing the sum of the squared residuals. To be precise, a single linear regression model could not provide an adequate description for generic databases and nonlinear model could not be appropriate either. Besides, its corresponding regression based distance measure would produce factual error. To overcome this problem, we propose a model using PLR [20] [21] to represent the shape of the distribution purified from the error.

\section{Piecewise Linear Regression (PLR)}

A problem which recurs occasionally is the estimation of regression parameters when the data sample is hypothesized to have been generated by more than a single regression model. This has been referred to as "piecewise linear regression" [22].

To state our problem, consider $Y$ as the response variable, and $X$ as the explanatory variables. Assume that there is a sample of $n$ observations. These observations are governed by a model of histograms. Our objective is to represent histogram by monotonic increasing piecewise linear regression with $k$ segments separated by a breakpoint $B P$. The simplest piecewise-regression model joins two straight lines sharply at the breakpoint as follows:

$$
\begin{aligned}
& y_{i}=m_{1} \cdot x_{i}+c_{1} \text { for } x_{i}<B P \\
& y_{i}=m_{2} \cdot x_{i}+c_{2} \text { for } x_{i}>B P
\end{aligned}
$$

where $y_{i}$ is the value for the $i^{\text {th }}$ bin, $x_{i}$ is the corresponding value for the independent variable, $m_{1}$ and $m_{2}$ are the slope of the line segments, $c_{1}$ and $c_{2}$ are the intercept at the $y$-axis. The present paper recommends the following procedure when fitting piecewise regression line.

\subsection{Estimate Breakpoint}

The major problem is to determine the number and location of the "break points" of the underlying regression systems. The procedure we employ is the examination of the first order derivative in histogram, similar to proposed by Howard Wainer [23]. Fun- 
damentally, the strength of the response of a derivative operator is proportional to the degree of dependent variable discontinuity at that point at which the operator is applied [24]. Therefore the histogram differentiation enhances local slope where there is a lot of discontinuity information in the source and deemphasizes areas where there is little information in the source. It can be found between each successive bins $i$ and $i+1$ using (2).

$$
y_{i}^{\prime}=y_{(i+1)}-y_{(i)}, 1<i<I
$$

where $I$ is the number of bins. Hence the places where the first order derivatives $y_{i}^{\prime}$ are large are identified as breakpoints. Through empirical analysis on data points we can decide the number of breakpoints in accordance with the number of histogram bins.

\subsection{Access Breakpoint}

The next problem was to determine which of these points are break points and which are simply bad data point which caused a spuriously high first derivative. Let us say that breakpoint occurs at point $j$ : we wish to determine if the parameters of the regression system determined by points $1-j$ are significantly different from those of points $j-n$, where $n$ is the total number of points. To do this we shall construct a confidence interval around $m_{1}$ and $b_{1}$, where $m_{1}$ and $b_{1}$ are the slope and the y-intercept respectively of the best fitting (in a least-squares sense) straight line for the points $1-j$. We then inspect our estimates of $m_{2}$ and $b_{2}$ (the same parameters, for points $j-n$ ) to see if they lie in the confidence interval. The uncertainty about the distribution of regression parameters indicates that the jackknife [25]-[27] would be useful to compute confidence intervals for the estimation of the parameter. The appendix contains a brief description of jackknifing.

It is clear that if a break point exists at all it is most likely that the first derivative is largest at that place. If, in fact, the regression systems about point $j$ are different, one can continue the same process by examining the second largest first derivative and if it is below point $j$, say at point $k$, repeat the above procedure for points $1-k$ and $k-j$. This can be continued until no further significant differences are obtained.

\subsection{Fit PLR}

In order to fit PLR, the histogram is converted to normalized cumulative histogram. Since the shape of the histogram is not monotonically increasing where cumulative histogram always has positive slope. The estimated break points are mapped at the respective position. Then, we shall connect each pair of adjacent points by a straight line, whose are represented by set of slopes and intercepts.

\section{Piecewise Linear Regression Line Distance Measure}

After having built the piecewise regression line, now this section proposes an approach to find distance measure between two piecewise regressions lines indeed distance be- 
tween two symbolic objects. The key idea is to find the area between consecutive breakpoints.

\subsection{Area Subdivision}

Consider parallel lines from every break point to other end piece regression line, about the $\mathrm{x}$ axis. This is done to split the area into subareas.

\subsection{Subarea Measure}

Now each subarea has one pair of parallel sides about to $\mathrm{x}$ axis and a pair of linear regression lines about to $y$ axis, hence each subarea can be considered as trapezium [16]. So area of trapezium characterizes the distance between two simple regression lines. For a pair of samples, two different cases are possible and are summarized below:

Case 1: When pair of lines are not intersected shown in Figure 1, area of trapezium $A$ is given by the following formula where $a$ and $b$ are the lengths of the parallel sides and $h$ is the perpendicular distance between the parallel sides.

$$
\begin{gathered}
A=\frac{1}{2}(a+b) \\
a=\left\|\frac{\left(-c_{2}\right)}{m_{2}}-\frac{\left(-c_{1}\right)}{m_{1}}\right\|, \quad b=\left\|\frac{\left(1-c_{2}\right)}{m_{2}}-\frac{\left(1-c_{1}\right)}{m_{1}}\right\|
\end{gathered}
$$

where $c_{1}, m_{1}$ are the intercept and slope of simple linear regression line 1 and $c_{2}, m_{2}$ are the intercept and slope of simple linear regression line 2.

Case 2: When pair of lines are intersected shown in Figure 2, area of trapezium $A$ is considered as two triangles where their heights are computed based on the intersection point $y_{i p}$ between two lines

$$
\begin{gathered}
A=\left(\frac{1}{2} * a *\left(y_{i p}-y_{i}\right)\right)+\left(\frac{1}{2} * b *\left(y_{i+1}-y_{i p}\right)\right) \\
x_{i p}=\left(\frac{c_{2}-c_{1}}{m_{2}-m_{1}}\right), y_{i p}=m_{2} * x_{i p}+c_{2}
\end{gathered}
$$

where $x_{i p}$ and $y_{i p}$ are intersection points between pair of samples.

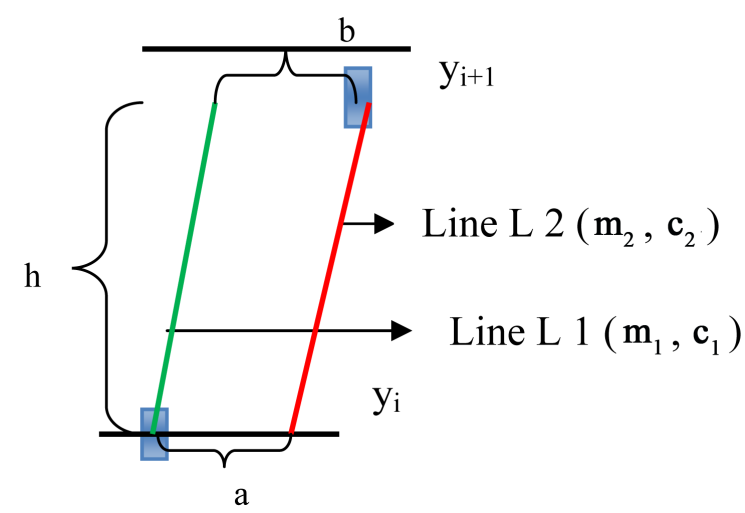

Figure 1. Pair of lines are not intersected. 


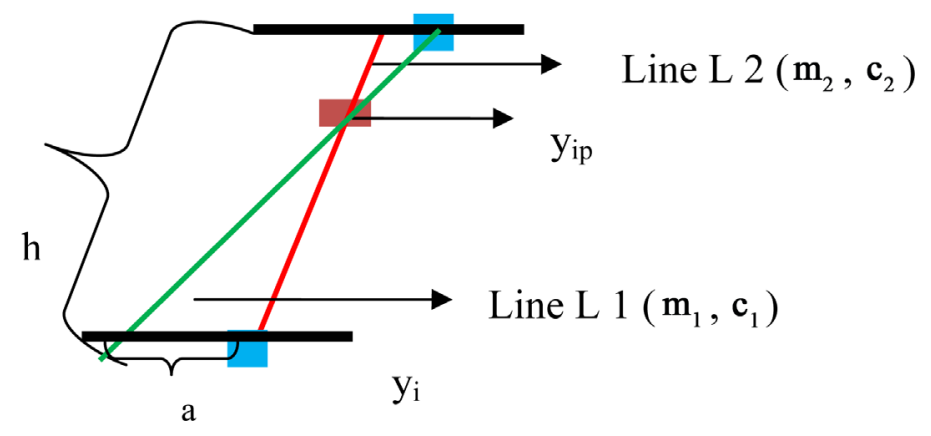

Figure 2. Pair of lines intersected.

\subsection{Summation of Distance Measure}

Distance computed from all sub region is summed up. A distance measure (also called a metric) is a dissimilarity Measure. The distance measure values closer to zero reveals that two symbolic objects have high similarity and vice versa.

\section{A Case Study on Real Data}

In this section, we propose a case study on real dataset. The case study refers to the quiz data pooled by a Learning Management Systems (LMS) called EkLuv-Ya [Ekl0] is used. EkLuv-Ya is the product created by Amphisoft Technologies for revolutionizing engineering education through Automated Evaluation Systems in different branches of engineering.

From the standpoint of the big data, the main objective of this case study is to show how the PLR summarizes the datasets in a meaningful and intelligent fashion, to its important and relevant features. Also how it enhances the data mining technique to mine knowledge pattern in big data. Hence we need to use a clustering technique in integration with SDA. Clustering is an unsupervised learning problem that group objects based upon distance or similarity. Each group is known as a cluster [28].

\subsection{Knowledge Pattern Discovery in LMS}

A typical web based LMS such as moodle [29] [30] in its simplest form provides a platform for online learning where educators can post their learning materials, assignments, tests etc and monitor progress of their students who in turn have to log in to learn from the posted material. An LMS [31] can keep record of all the student activities through their log files which pave way to gather large amount of data on a day to day basis. The amount of data which is gathered is proportional to the number of students registered for each course, number of times each student logs in for each of the registered courses and number of courses that are handled by an LMS. We can find streams of log records getting generated every moment, which makes the real time knowledge extraction almost impossible.

The datasets under investigation is the quiz data. It contains the marks scored in different quizzes by the 52 students of sixth semester of Bachelor of Engineering from Aditya Institute of Technology, Coimbatore (Tamil Nadu), India. The subjects of study 
in the order of appearance are: Computer Graphics, Mobile Computing, Numerical Methods, Object Oriented System Design and Open Source Software. For the sake of experimentation, minimum marks for each quiz is 2 and maximum marks for each quiz is 10. Marks of students who could not take up the quiz in a particular subject have been marked as " 1 ". The total number of bin taken is ten which is proportional to the number of quizzes. For bin size 10, the number of break point fixed is 1 .

\section{Results and Discussion}

The histogram matrix computed by summarizing the distribution of marks of ten quizzes under each of five subjects for every student is illustrated in Figure 3. Thereby providing users with the ability to visually analyze and explore large, complex datasets. The first derivatives were approximated and the largest derivative value location is determined.

Tukey's "jackknife" is used to test the meaningfulness of that breakpoint. For illustration, the data are shown in Figure 4. The first derivatives were approximated and the largest derivative was at point 7; we therefore examined the regression line of points $1-6$ and concluded, through jackknifing, that the parameters of the regression system were

\begin{tabular}{|c|c|c|c|c|c|}
\hline Subjects & \multirow{2}{*}{$\begin{array}{l}\text { Computer } \\
\text { graphics }\end{array}$} & \multirow{2}{*}{$\begin{array}{l}\text { Mobile } \\
\text { computing }\end{array}$} & \multirow{2}{*}{$\begin{array}{c}\text { Numerical } \\
\text { methods }\end{array}$} & \multirow{2}{*}{$\begin{array}{l}\text { Object } \\
\text { Oriented } \\
\text { System } \\
\text { design }\end{array}$} & \multirow{2}{*}{$\begin{array}{l}\text { Open } \\
\text { Source } \\
\text { software }\end{array}$} \\
\hline Students & & & & & \\
\hline S1 & 4 & 4 & 4 & 4 & 10 \\
\hline S2 & & 10 & 2 & 4 & \\
\hline S3 & 10 & 4 & 4 & 4 & 10 \\
\hline S4 & 5 & 4 & 4 & 4 & 4 \\
\hline$\cdots$ & & 2 & 2 & 2 & 2 \\
\hline S52 & & & & & \\
\hline
\end{tabular}

Figure 3. Summarization of very large data sets into symbolic histogram feature. 


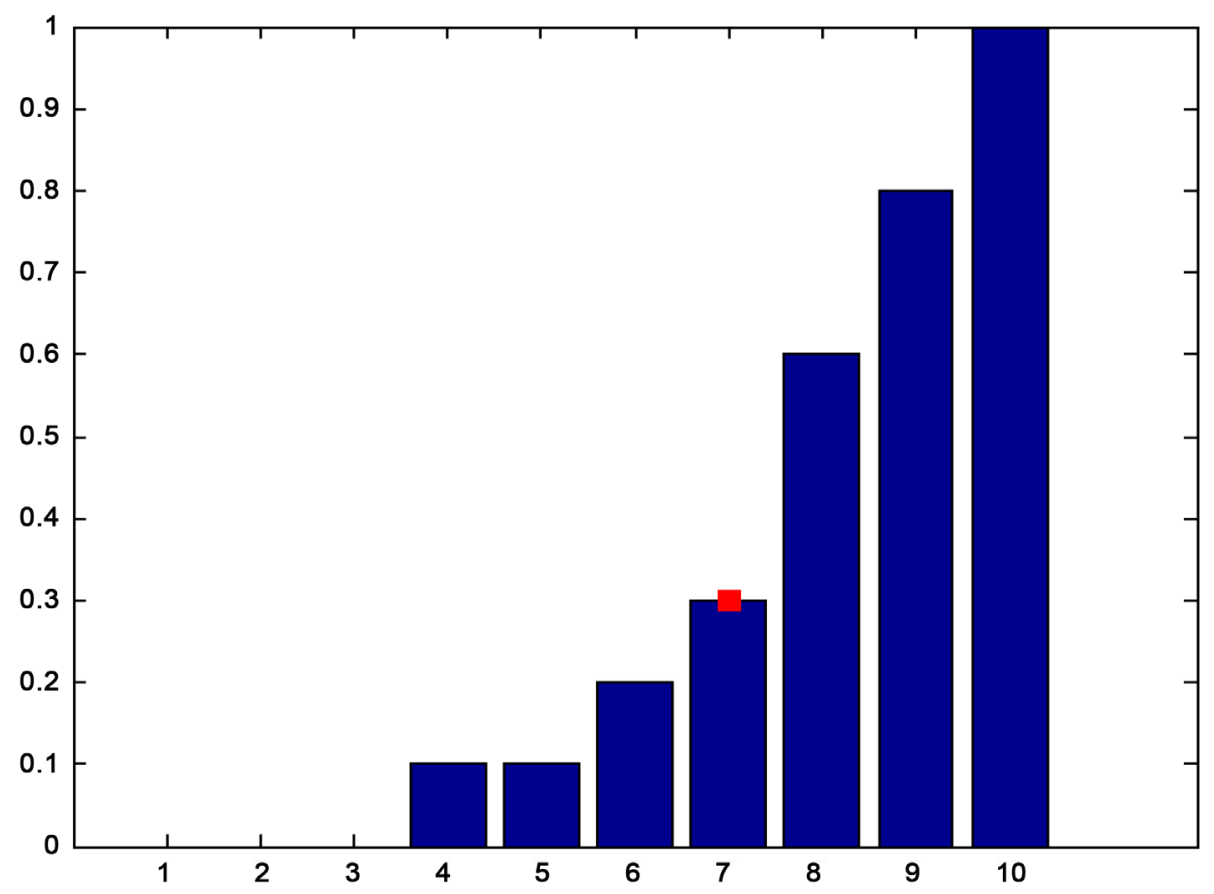

Figure 4. Number of quizzes versus mark frequency.

$$
\begin{gathered}
\operatorname{Pr}\left(0.10<M_{1-7}<0.24\right) \leq 0.98, \\
\operatorname{Pr}\left(-0.40<B_{1-7}<-0.60\right) \leq 0.98 .
\end{gathered}
$$

The points 8 - 10 were also jackknifed and yielded the following parameter estimates:

$$
\begin{aligned}
& \operatorname{Pr}\left(0.018<M_{7-10}<0.028\right) \leq 0.98, \\
& \operatorname{Pr}\left(-0.10<B_{7-10}<-0.20\right) \leq 0.98 .
\end{aligned}
$$

where $M$ and $B$ are the slope and the y-intercept of the regression line indicated. These two pairs of intervals do not even overlap and hence we concluded that point 7 was a break point.

Then histogram is converted to cumulative histogram Figure 5 and the breakpoint is mapped.

Piecewise regression line Figure 6 is fitted to the cumulative histogram according to the algorithm illustrated in the Section 3, which characterize the relationships and dependencies that exist within the histogram. Using $\mathrm{AB}$ distance measure dissimilarities between individual objects are calculated and the size of the matrix is $52 * 52 * 5$.

The obtained distance matrix is given as input to cluster analysis [32] to classify them into groups. The strength of the distance measure is portrayed by the dendrogram (Figure 7) of the obtained data set. The dendrogram [14] shows the merging of samples into clusters at various stages of the analysis and the similarities at which the clusters merge, with the clustering displayed hierarchically. There are 2 major classes obtained in the structure (Figure 7). The students grouped in cluster 1 (blue) have secured mark 


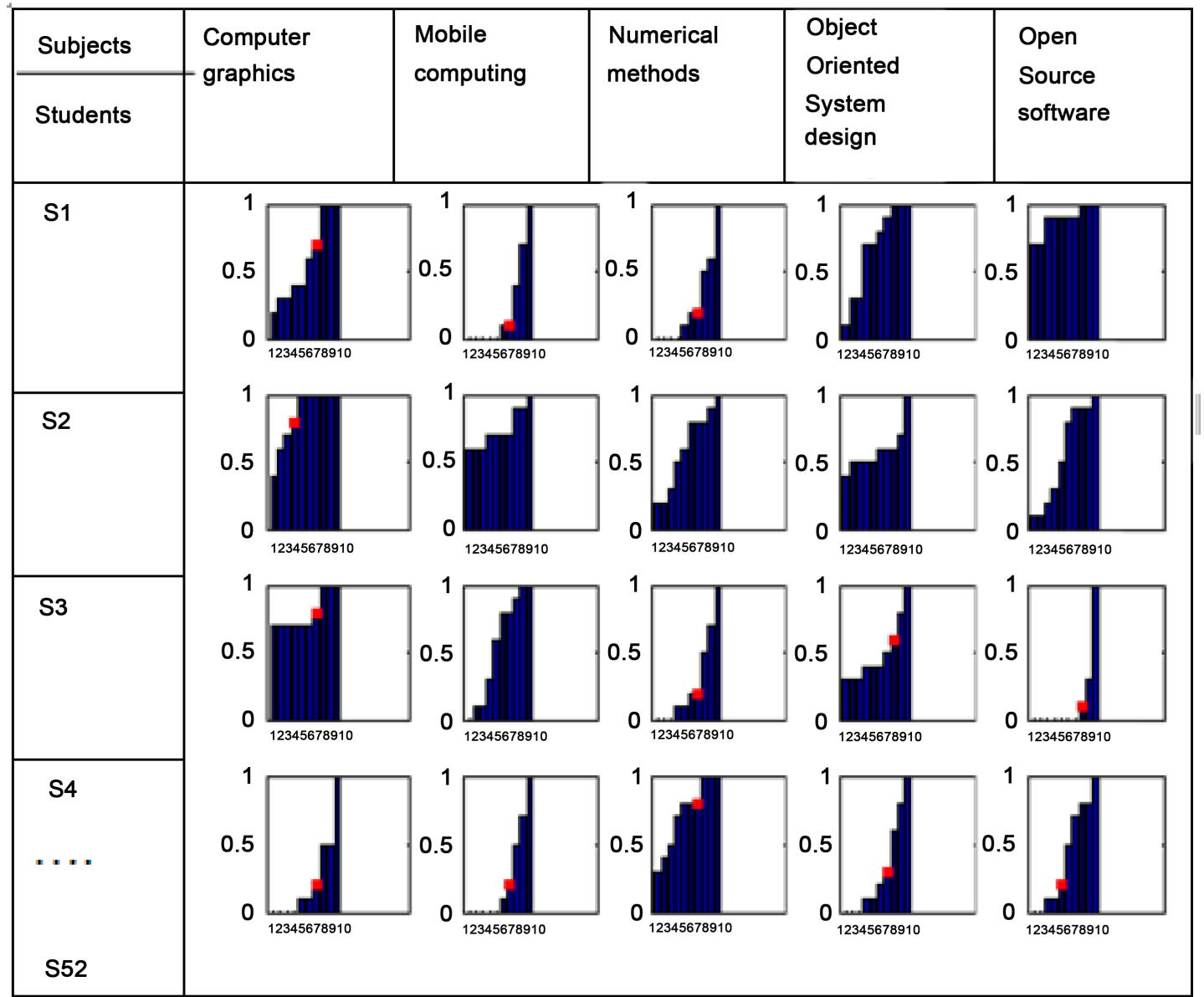

Figure 5. Cumulative histograms with breakpoints.

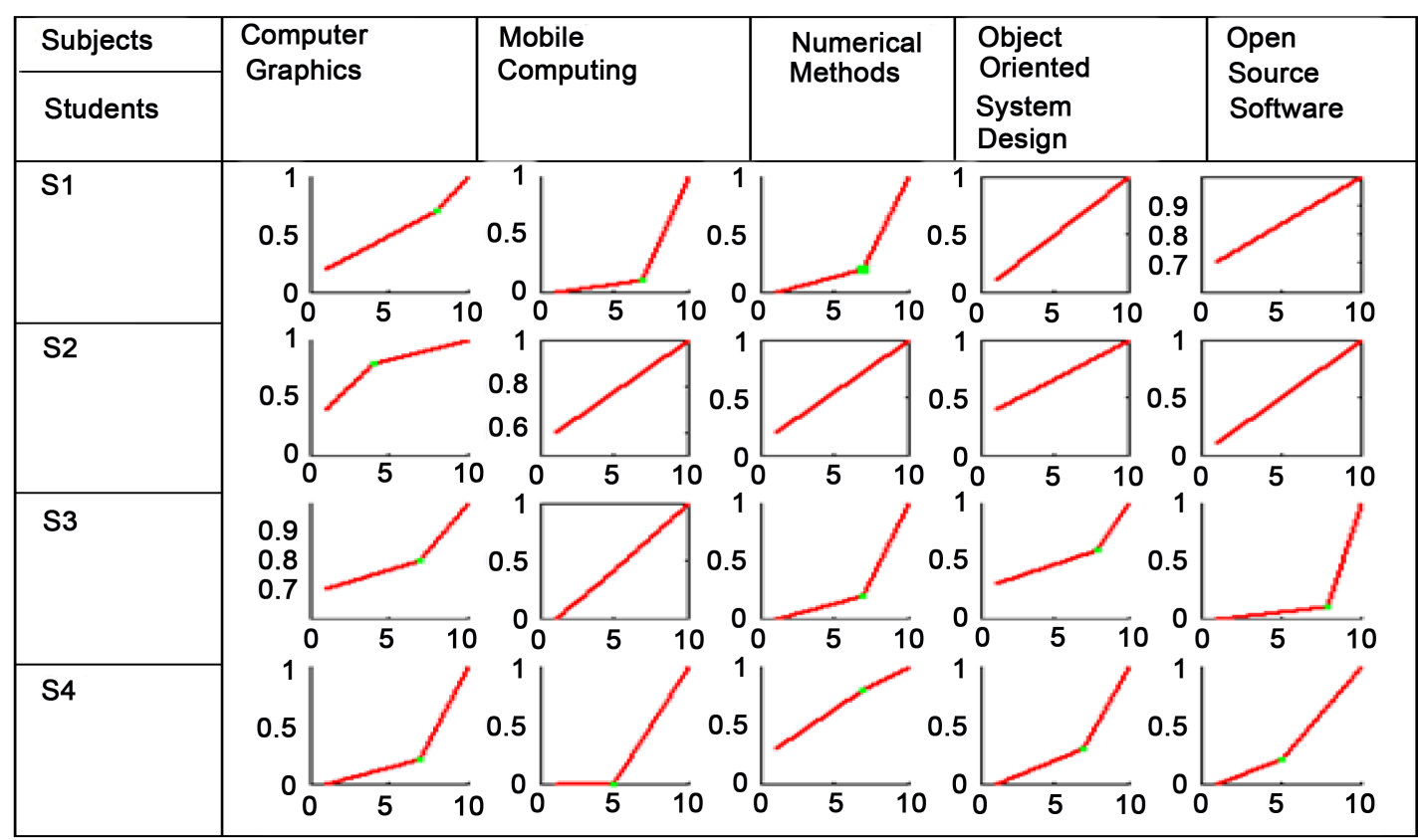

Figure 6. PLR features representing students performance. 


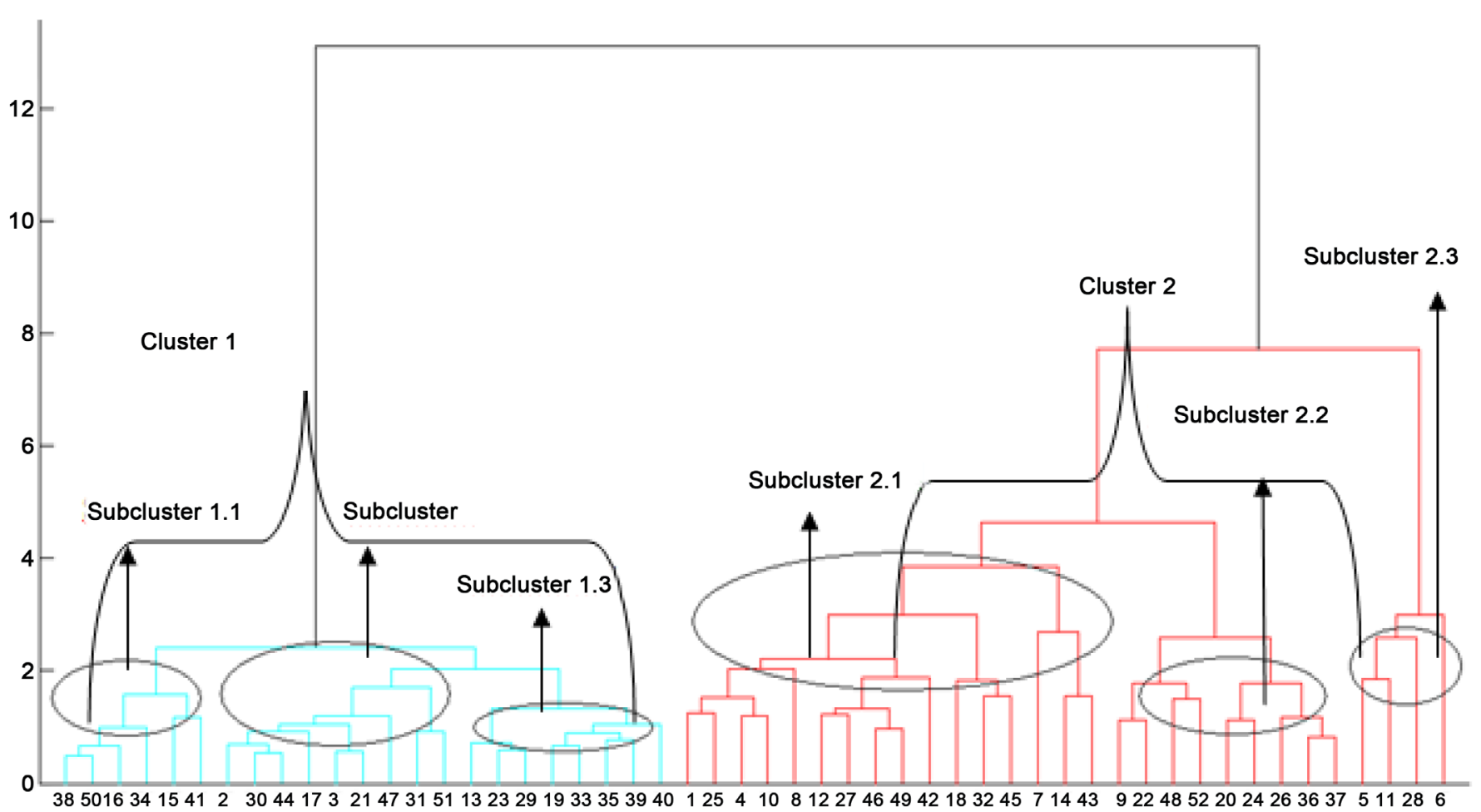

Figure 7. Dendrogram obtained through complete linkage clustering using AB distance measure.

above $70 \%$ which indicates good knowledge in subjects. Cluster 2 (red) students below $70 \%$ who have poor knowledge in subjects. In order to validate, obtained results when compared with teachers handling the subjects match exactly with the expected results. This experimentation will help the teacher in finding out the students of a particular group and counsel them as the information about serial number of students is retained as knowledge. Also it promises to enhance academic planner's sense of decision making which specific subject should be improved to achieve student learning effectiveness and progress [16].

\section{Conclusion}

Big data are a new phenomenon. Also a characteristic of modern large-scale data sets is that they often have a nontraditional form. New statistical methodologies with radically new ways of thinking about data are required. In that very important sense, PLR can be considered a method for Big Data which holds more details about the data in a compressed form which requires only two parameters sets-slope and intercept. Also PLR a powerful knowledge representative, instead of a histogram reduces the memory requirement and the computational complexity of this symbolic histogram. We employed Tukey's "jackknife" to test the meaningfulness of any suggested subdivision of the regression curve into pieces. To support our proposed theory we have done a case study in educational environment. It is expected that this work can be successfully used in different areas including financial, banking. 


\section{References}

[1] Adhikari, A. and Rao, P.R. (2008) Synthesizing Heavy Association Rules from Different Real Data Sources. Pattern Recognition Letters, 29, 59-71. http://dx.doi.org/10.1016/j.patrec.2007.09.001

[2] Fayyad, U., Piatetsky-Shapiro, G. and Smyth, P. (1996) Knowledge Discovery and Data Mining: Towards a Unifying Framework. Proceedings of the 2nd International Conference on Knowledge Discovery and Data Mining, Portland, Oregon, 2-4 August 1996, 82-88.

[3] Han, J. and Kamber, M. (2006) Data Mining-Concepts and Techniques. 2nd Edition, Elsevier, Amsterdam.

[4] Piatestsky, S.U., Smyth, M.A. and Uthurusamy, R. (1996) Advances in Knowledge Discovery and Data Mining. AAAI/MIT Press.

[5] http://www.infosys.com/trends/Pages/big-data-2014.aspx

[6] Diday, E. (1990) Knowledge Representation and Symbolic Data Analysis. In: Schader, M. and Gaul, W., Eds., Knowledge Data and Computer Assisted Decisions, Springer-Verlag, Berlin, 17-34. http://dx.doi.org/10.1007/978-3-642-84218-4_2

[7] Bock, H. and Diday, E. (2000) Symbolic Objects. In: Bock, H.-H. and Diday, E., Eds., Analysis of Symbolic Data, Springer-Verlag, Berlin, 54-77. http://dx.doi.org/10.1007/978-3-642-57155-8 4

[8] Billard, L. and Diday, E. (2002b) From the Statistics of Data to the Statistics of Knowledge: Symbolic Data Analysis. Journal of the American Statistical Association, 98, 470-487. http://dx.doi.org/10.1198/016214503000242

[9] Lazar, N. (2013) The Big Picture: Symbolic Data Analysis. CHANCE, 26, 39-42. http://dx.doi.org/10.1080/09332480.2013.845450

[10] Billard, L. and Diday, E. (2006) Symbolic Data Analysis. Conceptual Statistics and Data Mining. Wiley, Hoboken. http://dx.doi.org/10.1002/9780470090183

[11] Gioia, F. (2001) Statistical Methods for Interval Variables. Ph.D. Thesis, University Federico II Naples, Naples. (In Italian)

[12] Lauro, C.N. and Palumbo, F. (2000) Principal Component Analysis of Interval Data: A Symbolic Data Analysis Approach. Computational Statistics, 15, 73-87. http://dx.doi.org/10.1007/s001800050038

[13] Gibbs, A.L. and Su, F.E. (2002) On Choosing and Bounding Probability Metrics. International Statistical Review, 70, 419-435. http://dx.doi.org/10.1111/j.1751-5823.2002.tb00178.x

[14] Verde, R. and Irpino, A. (2010) Ordinary Least Squares for Histogram Data Based on Wasserstein Distance. Proceedings of COMPSTAT2010, Paris, 22-27 August 2010, 581-589. http://dx.doi.org/10.1007/978-3-7908-2604-3 60

[15] Kim, J. and Billard, L. (2013) Dissimilarity Measures for Histogram-Valued Observations, Communications in Statistics-Theory and Method, 42, 283-303. http://dx.doi.org/10.1080/03610926.2011.581785

[16] Pradeep, K.R. and Nagabhushan, P. (2007) An Approach Based on Regression Line Features for Low Complexity Content Based Image Retrieval. International Conference on Computing. Theory and Applications, Kolkata, 5-7 March 2007, 600-604.

[17] Signoriello, S. (2008) Contributions to Symbolic Data Analysis: A Model Data Approach. PhD Thesis, Department of Mathematics and Statistics, University of Naples Federico II, Naples.

[18] Boor, C. (1978) A Practile Guide to Splinea. Springer, New York.

[19] Dias, S. and Brito, P. (2011) A New Linear Regression Model for Histogram-Valued Va- 
riables. Proceedings of the 58th ISI World Statistics Congress, Dublin, 21-26 August 2011.

[20] Malash, G.F. and El-Khaiary, M.I. (2010) Piecewise Linear Regression: A Statistical Method for the Analysis of Experimental Adsorption Data by the Intraparticle-Diffusion Models Chemical Engineering Journal, 163, 256-263. http://dx.doi.org/10.1016/j.cej.2010.07.059

[21] Toms, J. and Lesperance, M. (2008) Piecewise Regression: A Tool For Identifying Ecological Thresholds. Ecology, 84, 2034-2041. http://dx.doi.org/10.1890/02-0472

[22] McGee, V.E. and Carleton, W.T. (1970) Piecewise Regression. Journal of the American Statistical Association, 65, 1109-1124. http://dx.doi.org/10.2307/2284278

[23] Wainer, H. (1971) Piecewise Regression: A Simplified Procedure. British Journal of Mathematical and Statistical Psychology, 24, 83-92. http://dx.doi.org/10.1111/j.2044-8317.1971.tb00450.x

[24] Gonzalez, R.C. and Woods, R.E. (2008) Digital Image Processing. 3rd Edition, Prentice Hall, Upper Saddle River.

[25] Bacon, D.W. and Watts, D.G. (1971) Estimating the Transition between Two Intersecting Straight Lines. Biometrika, 58, 525-534. http://dx.doi.org/10.1093/biomet/58.3.525

[26] Shao, J. and Tu, D. (1995) The Jackknife and the Bootstrap. Springer Verlag, New York. http://dx.doi.org/10.1007/978-1-4612-0795-5

[27] Abdi, H. and Williams, L.J. (2010) Jackknife. In: Salkind, N. and Frey, B., Eds., Encyclopedia of Research Design, Sage, Thousand Oaks.

[28] Lavine, B.K. (2012) Clustering and Classification of Analytical Data. In: Encyclopedia of Analytical Chemistry.

[29] Romero, C., Ventura, S. and Garcia, E. (2007) Data Mining in Course Management Systems: Moodle Case Study and Tutorial. Computers and Education, Elsevier Sciences Amsterdam.

[30] http://moodle.org/

[31] Miranda, E. (2011) Data Mining as a Technique to Analyze the Learning Styles of Students in Using the Learning Management System. 2011 Semimar Nasional Aplikasi Teknologi Informasi, 17-18 June 2011.

[32] Jain, A. and Dubes, R. (1988) Algorithms for Clustering Data. Prentice-Hall, Englewood Cliffs. 
Submit or recommend next manuscript to SCIRP and we will provide best service for you:

Accepting pre-submission inquiries through Email, Facebook, LinkedIn, Twitter, etc. A wide selection of journals (inclusive of 9 subjects, more than 200 journals)

Providing 24-hour high-quality service

User-friendly online submission system

Fair and swift peer-review system

Efficient typesetting and proofreading procedure

Display of the result of downloads and visits, as well as the number of cited articles

Maximum dissemination of your research work

Submit your manuscript at: http://papersubmission.scirp.org/

Or contact cs@scirp.org 